\title{
Investigation of tax benefits as tool for charity activities stimulation
}

\author{
Anna Kireenko \\ The Department of Taxation and Customs \\ Baikal State University \\ Irkutsk, Russian Federation \\ KireenkoAP@bgu.ru
}

\author{
Sofia Golovan \\ The Department of Finance and Accounting \\ Irkutsk State Transport University \\ Irkutsk, Russian Federation \\ free9sonjas@gmail.com
}

\begin{abstract}
The article explores the issues of government measures to promote the commercial organizations' participation in charitable activities. The reporting data of banks, represented in Irkutsk region, are used as the empirical basis for the study. The study has used a sample of 49 banks, operating in Irkutsk region in 2011-2014. The research is based on the assumption that the preferential taxation reduces the cost of charitable services for the company. The authors set two main tasks: to construct a theoretical model, describing the tax benefit effect on financial contribution to the charitable sector, and to find the optimal limit for charitable spending, as a part of expenses reducing the taxable profit of the company. The authors concluded that there is the hypothetical possibility of increasing charitable donations as the result of introducing preferential taxation. The optimal limit of charitable expenses for tax purposes is up to $5 \%$ of the taxable profit. It is rationale to provide this optimal limit taking into account the budget efficiency.
\end{abstract}

Keywords - preferential taxation, charitable spending, state stimulation, tax benefit

\section{INTRODUCTION}

The promotion of the non-governmental non-profit sector is considered now to be one of the important directions of public policy. For the most part, it is the matter of building a new system of interaction between the state and non-profit sector in terms of financial resources redistribution in favor of the non-profit sector to fulfill important social functions and tasks. On the other hand, charity expenses of the commercial sector are aimed at similar socially important spheres such as the expenses of socially oriented non-profit organizations. Accordingly, the tax incentives for charitable activities of commercial organizations can be analyzed as a measure of the additional state funding of the nonprofit sector, dealing with socially relevant issues.

The article presents the model of the introduction of preferential tax treatment for the charitable activities of commercial organizations using the banking sector as an example.

The awareness of charitable tax deduction influences the amount of giving which has grown in recent years but remains incomplete. The empirical evidence shows that the amount of giving is at least partly sensitive to the cost of giving. The evidence also suggests that giving is fairly responsive to temporary changes in the cost of giving, though few researchers agree on how sensitive it is to more permanent price changes. But much remains to be learned, especially about charitable giving in the Russian Federation, where charity is not so extensive as in OECD countries (Bennett, 1998). The ability to deduct the costs of charitable donations from taxable income existed in the Russian tax law before 2002 , but today there are no tax benefits available to corporate donors in Russia.

The economic impact of preferential taxation system introduction compared to a direct budget financing of socially important directions should be analyzed via the changes in the volume of attracted funds in response to the decrease in the cost of charity work for the company. In economics, this concept is called "price elasticity of charitable expenditure») (Scharf et al, 1997).

Since the reduction in the cost of charity work for the company is financed by tax revenue shortfall of the budget, the price elasticity reflects the effectiveness of tax incentives as a way of indirect subsidizing socially oriented non-profit organizations. While high price elasticity shows the excess of total expenditure over the attracted charity budgetary losses, low price elasticity shows the opposite effect. Thus, the limitation of the charitable expenditures' value for commercial organizations is an important issue that may be taken into account for tax purposes. The limit must be valuable enough to stimulate the commercial organizations to increase their spending, but at the same time, this limit should not restrict tax revenue of state and regional budgets.

\section{LITERATURE REVIEW}

There is abundant literature on the analysis of charity and the study of economic and non-economic factors affecting its output. For example, in a study conducted by C. Clotfelter on the data for the period of 1936-1980, an undoubted positive effect of preferential taxation in the United States in respect of corporate charity was described. He also noted the strong role played by private donations in funding the non-profit sector (Clotfelter et al, 1997). Regarding the differences in the value of corporate philanthropy that depend on the area of activity, there was a link between communications with consumers of goods and services of the organization and the work in the field of charity (Clotfelter \& Steuerle, 1981). So the largest share in the profit value of charitable contributions belonged the banking sector and trade in food and other essential commodities. According to C. Clotfelter, this can be explained 
in terms of the value which the management and owners of the company consider to be essential for the formation of a positive image of their company. The effect of preferential tax treatment on increasing the volume of charitable activities has been studied by G.Fack and C. Landais (2010). According to their findings, the response of a donor to preferential tax treatment depends largely on the volume of donations made earlier. Therefore, in their research, the authors concluded that after the reform in France more generous donors had responded faster to the tax credit rate increase for donations. So, they note that a high tax credit rate in France can be economically justified, based on the premise that private foundations are able to perform many tasks more efficiently than the state is.

The earliest studies showed a relatively low degree of elasticity of charitable activity, proving the hypothesis that the tax credit is an inefficient way of financing public goods and services (Johnson, 1981). The data that are more recent indicate high elasticity of charitable expenditure. However, it is not sufficiently high to say that the tax credit is a more preferred tool then the direct financing (Steinberg, 1995; Barrett et al, 1997). At the same time, most researchers agree that the tax credit might allow increasing additional financial resources. At the same time, the tax credit is able to decrease the number of disadvantages inherent to direct grants and subsidies for socially oriented (socially useful) non-profit organizations (Duff, 2004).

At the same time, there are opinions that the tax credit and deduction can be the instrument to reduce poverty as well as the progressive taxation scale and the tax-exempt minimum (Pinskaya, 2016). The authors of this paper also analyzed the influence of preferential tax treatment on charitable expenses of commercial organizations in their previous papers (Kireenko \& Golovan, 2016).

\section{III.DATA AND METHODS}

In the Russian Federation, there are no tax benefits available to corporate donors. An individual can claim a charitable deduction up to $25 \%$ of their taxable income. The ability to deduct the charitable donations from taxable income had existed in the Russian tax law before 2002. In accordance with the law "On taxes on profits of enterprises and organizations", passed on 27.12.1991, corporate taxpayers were allowed to deduct the charitable donations up to $5 \%$ of their taxable income per year from their tax base (banks and insurance companies up to $3 \%$ ). The tax incentives for businesses, involved in charitable activities, were canceled in 2002, when Chapter 25 of the Tax Code came in effect. According to the Letter of the Russian Ministry of Finance, if the firm provided free services or donated its products, the costs, which arose at the same time, did not reduce the firm's payments to the budget. In the literature of that period, tax incentives for charity were described as an example of negative, inefficient use of tax mechanism. There was an opinion that commercial organizations were not motivated to make donations due to the low level of trust to the tax system. In this study, we considered the various limits of tax deduction: $1 \%, 3 \%, 5 \%$, and up to $10 \%$. For the purpose of the study, we understand tax relief as a certain percentage reduction in the CIT tax base. To assess the possible growth of charity benefits, we worked out the following algorithm:

Step 1. At this step, the authors selected the number of the banks working in Irkutskaya Oblast, which had successfully passed the Central Bank control. These banks were grouped according to the amount of capital in accordance with their reports of the year 2011. The authors also used the financial data on the income, the volume of charitable expenses, and current income tax for the period of 2011-2014.

Step 2: The calculation of the various limits of tax deduction for charitable expenditure spent by the given number of banks for the period of 2011-2014 was done.

Step 3: The authors compared existing expenses of the banks with the calculated limits.

Step 4. For the banks, where existing expenses do not exceed the prescribed limits, the possible increase of charitable expenditure was calculated. This possible increase should be compensated through the mechanism of preferential tax treatment, the so-called "potential to increase donations."

Step 5. The summation of existing expenses and the potential to increase in each bank for the respective years was calculated.

Step 6: The comparison of the amount received with the value of the hypothetical limits was made.

Step 7. For the banks where the expenses exceeded the limit, the full potential of an increase would be equal to the difference between the amount of the limit and the amount of the existing expenses and should be considered as fixed at a submaximal level.

Step 8. For the banks where the amount does not exceed the calculated limit, the full potential should be considered as fixed at the maximum level.

The study based on a number of banks operating in one region of the Russian Federation, Irkutsk Oblast in 2011-2014 years. In order to improve the quality of the study, the banks which the Central Bank suspected of dubious performance reports, were not taken into account. Thus, the survey covered 49 banks represented in Irkutskaya Oblast. The study sample was divided into three groups according to the principle of social responsibility of banks in the United States (Cornett, 2013). According to this principle, the first group had the banks with the volume of their own funds less than 10 billion rubles (small banks).The second group had the banks with the volume of capital more than 10 billion but less than 100 billion rubles (medium-size banks). The third group had the banks with the volume of their own funds more than 100 billion rubles (large banks). To obtain the data on the degree of involvement of the investigated banks in corporate philanthropy, the authors used the information provided on the official banks websites, and the information provided in annual reports.

The calculated data of charitable expenses and the net profit of the three groups of selected banks are presented in Table 1. As one can see from the table, the average volume of charity spending committed by the banks grew steadily 
throughout the study period. To assess the quality parameters of the banks' participation in charitable activities, we used the criteria developed by the Czech researchers based on the banking system of the Czech Republic (Burianová, 2014). These options were designed to assess the level of corporate social responsibility of banks. In order to evaluate the participation of the banking system in charity, these options have been adapted to meet the needs of our study.

TABLE I. THE DYNAMICS OF CHARITABLE EXPENSES AND NET INCOME OF THE INVESTIGATED BANKS DIVIDED BY THE SIZE THEIR FUNDS FOR THE YEARS 2011-2014

\begin{tabular}{|l|r|r|r|r|c|}
\hline $\begin{array}{l}\text { Indicator / } \\
\text { year }\end{array}$ & 2011 & 2012 & 2013 & 2014 & $\begin{array}{l}\text { Growth } \\
2014 / \\
2011, \%\end{array}$ \\
\hline $\begin{array}{l}\text { The average } \\
\text { volume of } \\
\text { expenses, } \\
\text { thousand } \\
\text { rubles }\end{array}$ & 128026.4 & 164213.2 & 185299.8 & 230439.3 & 79.9 \\
\hline $\begin{array}{l}\text { In the group } \\
\text { of small } \\
\text { banks }\end{array}$ & 485.8 & 408.4 & 451.9 & 527.9 & 8.7 \\
\hline $\begin{array}{l}\text { In the group } \\
\text { of medium- } \\
\text { sized banks }\end{array}$ & 68904 & 69694.2 & 42081.8 & 25430.5 & 63.1 \\
\hline $\begin{array}{l}\text { In the group } \\
\text { of large } \\
\text { banks }\end{array}$ & 474914.6 & 650623 & 758332.5 & 1061551.5 & 123.5 \\
\hline $\begin{array}{l}\text { The average } \\
\text { volume of } \\
\text { net profit, } \\
\text { thousand } \\
\text { rubles }\end{array}$ & 10549761 & 12175842 & 13204975 & 10700570 & 1.4 \\
\hline $\begin{array}{l}\text { In the group } \\
\text { of small } \\
\text { banks }\end{array}$ & 266823.9 & 435023 & 371551 & 353106 & 32.3 \\
\hline $\begin{array}{l}\text { In the group } \\
\text { of medium- } \\
\text { sized banks }\end{array}$ & 2475960 & 3267787 & 2364711 & 1343119 & 45.8 \\
\hline $\begin{array}{l}\text { In the group } \\
\text { of large } \\
\text { banks }\end{array}$ & 45793115 & 51732955 & 55677373 & 47462622 & 3.6 \\
\hline
\end{tabular}

Thus, we suppose that the main elements of the existing involvement of banks in support of socially important issues today, are:

- Publication of social reports on the results of the work done

- Provision of open and full information on the types and forms of charitable activities and supported recipients on the company's official website

- Involvement of employees in charity support, and encouragement of voluntary initiatives in the company team
- Creation and active introduction of banking products for charity

- Availability of long-term sustainable strategy for charitable activities in the framework of corporate social responsibility

Based on the data of the banks represented in Irkutskaya Oblast, the authors can conclude that the existing volume of banks' own contributions to charity exceeds the limit of $10 \%$ of taxable profit at a few banks. Therefore, it will not make sense for the proposed model to consider the limit of more than $10 \%$. Thus, in this study we tested only the limits of $1 \%$, $3 \%, 5 \%$ and $10 \%$ of the taxable income. One can determine the maximum amount of charitable donations of each bank basing on the following assumptions:

Tax deduction should reduce the cost of charitable expenses for the donor. However, one should understand that this measure matters only for the companies that have already been involved into charitable activities and have already had charitable expenses. If the bank does not participate in charity and does not have charitable expenses, one cannot expect that the introduction of tax deduction will be a motivating factor.

If, at the end of the period, the company recorded losses, but made charitable donations, one cannot use the amount of the possible donation in the model. Since the company does not have any profit, the deduction of tax on this profit will not motivate it.

If the amount of the organization's existing expenses exceeds the volume of hypothetical donations we also cannot consider this excess in the model. As a privilege this money will not cover the entire amount of committed expenditure; therefore, it makes no sense to speak about these benefits.

If an increase in the bank's existing expenses compensate the benefits above the specified limit of taxable income, the amount of possible charitable donation could be increased to the size which will be covered by the tax incentive. Since the further increase in this case occurs at the expense of net profit, it would not be possible to estimate the degree of influence of this preferential tax treatment. Such volume of donations in the model considered as sub-maximal.

In the framework of the model, if the amount of the existing expenses increase by the volume equal to the benefit compensated, and the compensated amount does not exceed the limit allowed for tax purposes, this increase considered as the maximum amount of donations for the organization.

\section{IV.RESULTS}

The study provided the data on the prevalence of charitable activities among the banks based on the selected quality indicators (Figure 1). The information on the forms and directions of charitable activities in the organization can be found on the official websites of $67.3 \%$ of banks. Based on the $95 \%$ confidence intervals, one can say that it is equal to $53.8 \%-80.2 \%$ of the total population of banks in the Russian Federation. Reference to long-term partnerships with a particular recipient of donations or prioritized charitable activities was found in 46.9 percentage of the banks [95\% CI $32,9-60,8]$. Promotion of volunteer initiatives in the team, 
as well as organization of volunteer projects, takes place in $28.5 \%$ of the banks [95\% CI 15,8 - 41,1], and the development of banking products oriented to charity takes place in $38.7 \%$ [95\% CI 25,1 - 52,3].

Regarding the investigated differences of banks involvement in charity, which depends on the size of the capital, one can say that most of the indicators are significantly higher in the group of large banks than among other banks involved in philanthropy $(\mathrm{p}<0.05)$.

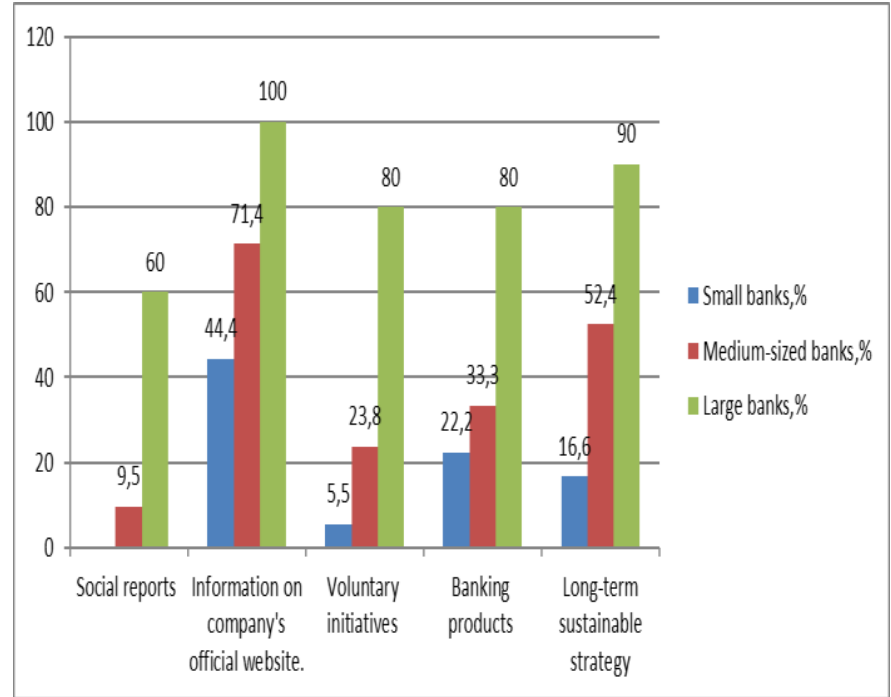

Fig. 1. Differences in the degree of involvement into charity, depending on the size of the bank's capital

Thus, information about the organization's philanthropy could be found on the official websites of $44 \%$ of small banks [95\% CI 21,2-66,9], 71.4\% medium-sized banks [95\% CI $52,1-90,7]$, and on the websites of all large banks without any exception. Volunteer work in the organization is encouraged by $5.5 \%$ of small banks [95\% CI 5-16,03] and $23.8 \%$ of medium-sized banks [95\% CI 5,6 - 42,01], while $80 \%$ of the large banks in the study group [95\% CI 55,2-104,8] mentions projects that involved their employees. It should be noted that the study has revealed an interesting trend: while the big banks are much more involved in charitable activities than small banks according to all evaluated parameters ( $\mathrm{p}<0,05)$, the differences between the involvement of medium and large banks have been identified only in terms of these expenses value for the bank. Because of the lack of information about the forms and types of charitable activities on the banks sites, it is difficult to conclude about the differences in the group strategy on charity. However, other indicators for large banks differ from the small and medium-size bank indicators. While some expenses indicators of medium-size banks are already closer to those of the larger banks, medium-sized banks still differ from the large banks. This may be explained by the limited available financial and human resources of mediumsized banks. Therefore, they are ready to increase participation in charity, but do not have enough opportunities to adequately inform the public about their activities and to support the charity in various forms, not just in the form of direct cash donations.
Figure 2 shows the mechanism of the preferential taxation, depending on the various donation limits.

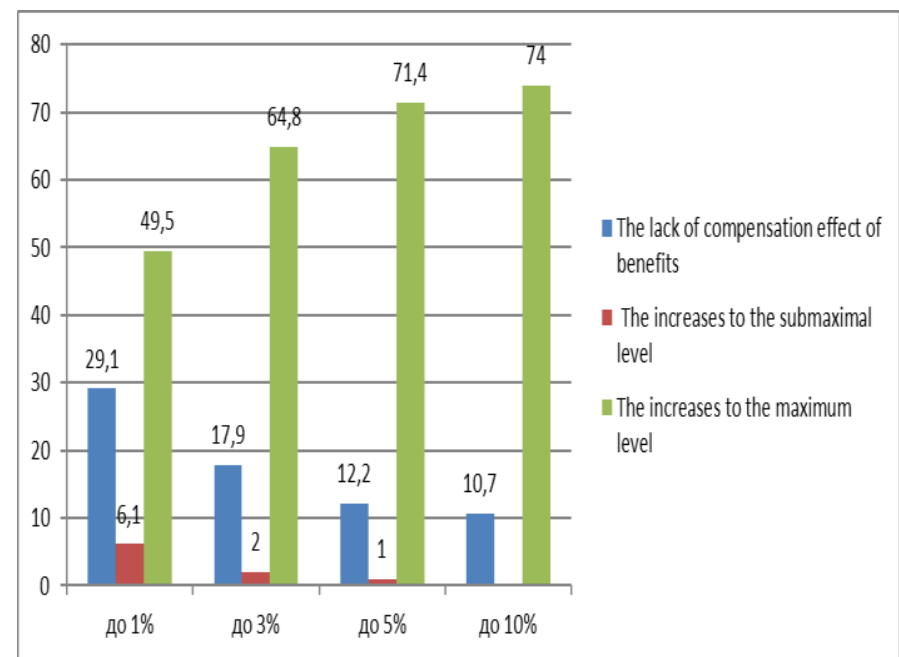

Fig. 2. Impact of preferential taxation depending on the limit of charitable donations

Based on Figure 2, one can conclude that setting any limit to deduct charitable donations from the profit can form the potential to increase charitable expenditure for most banks. In addition, most banks could form the potentially maximum level to increase in the model. Thus, having the limit of up to $1 \%$ of the taxable profit, the number of banks that could increase their donations to the maximum volume amounted to $49.5 \%$ of all the banks operating in Irkutskaya Oblast. On the basis of confidence intervals, one can assume (with $95 \%$ probability) that in case of the introduction of preferential taxation with setting $1 \%$ limit for charitable expenses, share of banks where the benefit would form the potential to maximize, would be in the interval from $42.5 \%$ to $56 \%$ of the banks in the Russian Federation. In the transition from the lowest limit to each subsequent, the average share of banks in this group gradually increases from $61.9 \%$ to $80 \%$ of the banks.

At the same time, the share of banks, which have not increased their spending, is relatively high at $1 \%$ limit, ranging from $22.7 \%$ to $35.5 \%$ of all banks. Changing the number of banks belonging to this group is the opposite to the change in the group with the potential to maximize, and falls to a relatively small number of $10.7 \%$ at the maximum limit. The share of banks that did not make donations and, consequently, for which tax benefit could not be a motivating factor, ranges from $3.8 \%$ to $22.8 \%$ and is independent on the set limit. There are banks in the considered sample $(2 \%)$ that made charitable spending but ended the year with negative financial performance. So, it was not possible to determine the potential to increase, caused by the benefits due to the lack of income tax base. The share of banks, whose potential to increase charitable donations to a set maximum limit was close to the limit and, therefore, stopped at sub-maximal level, ranges from $1 \%$ to $6.1 \%$, and depends on the set limit. But there is no bank reaching the limit of $10 \%$ in this group.

Since there are no tax incentives for philanthropist in the Russian Federation, three hypotheses about the price elasticity 
of charitable expenditure can be generated with the construction of the model:

$|\mathrm{E}|>1$, or elastic demand. In this embodiment, the increase rate of charitable expenses is faster than the decrease rate of charitable costs of the company.

$\mathrm{E}=1$, or a unit elasticity. The increase rate of charitable expenses is equal to the decrease rate of charitable costs of the company.

$0<\mathrm{E}<1$, or inelastic demand. The increase rate of charitable expenses is less than the decrease rate of charitable costs of the company.

In this paper, the indicator of the increase of the average value of charitable expenditure was used as a measure of socio-economic efficiency of the tax benefits. The results of preferential tax treatment introduction were compared with the planned targets. This indicator can be generally described as the potential for charitable expenses increase. This is the amount by which a particular organization could increase their charitable expenses by compensation effect from the introduction of the tax benefit (Andreoni et al, 2002).

Based on the data on the charitable expenses for the period of 2011-2014, the decline rate in the value of the charitable activities of the company was determined as a result of preferential tax treatment introduction. Thus, the cost of charitable expenses for the company without benefits and at the existing CIT rate of $20 \%$ can be described by Formula 1:

$\mathrm{S}^{\mathrm{P}}=\mathrm{G}^{\mathrm{f}}+0,2 \mathrm{G}^{\mathrm{f}}$,

$\mathrm{S}^{\mathrm{P}}$ - value of charitable expenses; $\mathrm{G}^{\mathrm{f}}$ - existing volume of company's charitable expenses; $0,2 \mathrm{G}^{\mathrm{f}}$-corporate income tax levied on charitable expenses without benefits.

Formula 2 demonstrates the reduction of the cost of charitable spending after the introduction of the tax incentive in comparison to the cost without benefits:

$$
\mathrm{S}^{\mathrm{P}}=\left(\left(\mathrm{G}^{\mathrm{f}} /\left(1,2 \mathrm{G}^{\mathrm{f}}\right)\right) * 100 \%\right)-100 \%=16,7 \%
$$

$\mathrm{S}^{\mathrm{P}}$ - value of charitable expenses; $\mathrm{G}^{\mathrm{f}}$ - existing volume of company's charitable expenses;

Based on formula 2, the volume of charitable expenses with the introduction of preferential tax treatment decreases by $16.7 \%$. It would be useful to compare the obtained volume with the rate of increase in costs to evaluate the price elasticity. The presence of the limit is an important part of tax incentives effectiveness (Duff, 2004).

Accordingly, in cases where the existing expenses of the organization exceed the limit of the taxable income and the CIT rate is $20 \%$, formula 2 will take the form of formula 3 :

$$
S^{p}=\frac{1,2 G^{f}-0,2 \text { Limit } P^{\operatorname{tax}}}{1,2 G^{f}}
$$

$\mathrm{S}^{\mathrm{P}}$ - value of charitable expenses, LimitP ${ }^{\mathrm{tax}}$ - the limit of the amount of charitable expenses for tax purposes; $G^{f}$ existing amount of company's charitable expenses.

Using this formula, on the basis of existing expenditure of banks for the period of 2011-2014, it is possible to determine the decrease in the value of charity for the company in case the amount of committed expenditure exceeds the limit.

The analysis of changes in financial costs of the charity in response to the decline in net value of charitable activities was done. An analysis of the average elasticity coefficients for the selected banks was done using various limits, and the range of elasticity coefficient variation for all banks was of $95 \%$ probability. Since the reduction in the cost of charity in the company is compensated by tax revenue shortfall of the budget, the resulting coefficients reflect the efficiency of tax incentives as the way to subsidize socially important issues. Thus, setting the appropriate limit should increase charitable expenses in accordance with the developed model.

Table 2 shows the results. Based on these findings, one can say that the preferential taxation impact is expressed in the growth of the volume of charitable spending in response to the decline in their value to the company. It can be considered a statistically significant difference with the limit of $1 \%$. This limit can be considered the least effective mechanism to stimulate the growth of charitable expenses.

TABLE II. ESTIMATION OF PRICE ELASTICITY OF CHARITABLE EXPENSES IN THE BANKING SECTOR WITH THE INTRODUCTION OF THE TAX BENEFIT AND THE MAXIMUM INCREASE IN THE MODEL, BASED ON THE FOUR -

\begin{tabular}{|c|c|c|c|c|c|c|}
\hline \multirow{2}{*}{$\begin{array}{l}\text { Limit } \\
\text { referring } \\
\text { charity } \\
\text { costs to } \\
\text { expenses } \\
\text { for tax } \\
\text { purposes }\end{array}$} & \multicolumn{2}{|c|}{$\begin{array}{l}\text { The } \\
\text { theoretical } \\
\text { reduction the } \\
\text { cost of } \\
\text { charitable } \\
\text { expenditure }\end{array}$} & \multicolumn{2}{|c|}{$\begin{array}{c}\text { Theoretical growth } \\
\text { of charitable } \\
\text { expenditure }\end{array}$} & \multicolumn{2}{|c|}{$\begin{array}{c}\text { Price elasticity of } \\
\text { charitable } \\
\text { expenditure }\end{array}$} \\
\hline & $\%$ & $\begin{array}{c}95 \% \\
\text { CI }\end{array}$ & $\%$ & $95 \% \mathrm{CI}$ & $\begin{array}{c}\text { coefficie } \\
\text { nt }\end{array}$ & $95 \% \mathrm{CI}$ \\
\hline Up to $1 \%$ & 12 & $\begin{array}{c}10.8- \\
12.8\end{array}$ & $14.4^{*}$ & $12.4-16$ & $\begin{array}{c}E= \\
{[0.87]}\end{array}$ & $0.75-0.9$ \\
\hline Up to $3 \%$ & 13.6 & $\begin{array}{c}12.8- \\
14.5\end{array}$ & 18 & $16.4-19.6$ & $\begin{array}{c}E= \\
{[1.32]}\end{array}$ & $0.9-1.8$ \\
\hline Up to $5 \%$ & 14 & $\begin{array}{c}13.1- \\
14.9\end{array}$ & 19.8 & $18.3-21.3$ & $\begin{array}{c}E= \\
{[1.19]}\end{array}$ & $1-1.4$ \\
\hline Up to $10 \%$ & 14.7 & $\begin{array}{l}13.9- \\
15.5\end{array}$ & 20.1 & $18.8-21.6$ & $\begin{array}{c}E= \\
{[1.21]}\end{array}$ & $1-1.4$ \\
\hline
\end{tabular}
YEAR PERIOD

On average, this limit would decrease the value of charity by $12 \%$, which could lead to an average increase of charitable expenses by $14.4 \%$ based on the maximum growth in a model by $25 \%$ (fig. 3 ). Thus, the average coefficient of elasticity would have amounted to 0.87 [95\% CI 0,75-0,9], which indicates low elasticity of charitable activities in response to 
the tax incentives and implementation of their capacity to increase the charitable expenditure.

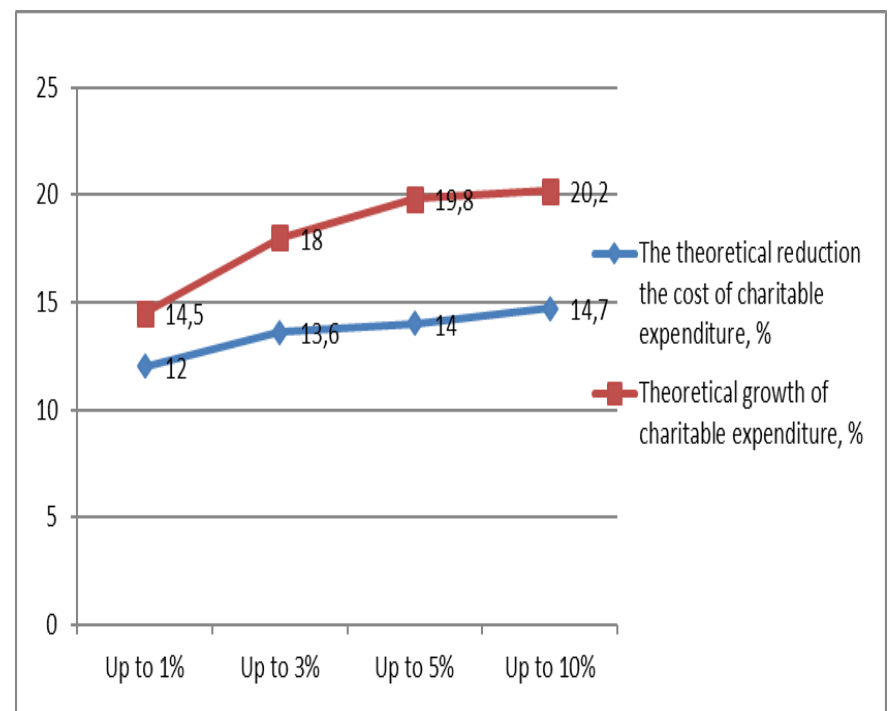

Fig. 3. The dynamics in the cost of charity for the banks and charitable expenses based on the four-year period, \%

At the same time, with the changes of limits by $3 \%, 5 \%$ and $10 \%$, statistically significant differences in the impact of benefits did not reveal. Accordingly, it is necessary to use precise criteria, which will be mentioned further in the search for the optimum limit registration of charitable expenditure. Optimum, on the one hand, would mean that it is high enough not to exceed the amount of most companies' actual costs without relying on economic incentives, and, on the other hand, low enough not to increase budget losses according to the shortfall in tax revenues from the companies, which are not expected to raise the expenditure in any case.

In order to prove that the effect of the preferential taxation mechanism increases spending, it is necessary to refute the "null hypothesis" about the lack of relation between the benefits and increase of charitable spending. For this purpose, in this study we used Wilcoxon test as a statistical tool. This is the criterion used to compare two indicators of changes in various conditions on the same test sample. It can be used to determine whether one indicator in a certain direction is more significant than the other. The method presupposes that the absolute dimensions of value changes are compared in a particular direction. To use the method, you must first compare all the absolute values of shifts with the rank, and then sum up all the ranks. If the one assumes that changes occur accidentally, the ranks of the amount should be about the same. If the intensity shifts in one direction is greater than the sum of ranks, it will be lower than for random variations. This criterion is a non-parametric, but limited by the sample size from 5 to 50 study items.

With respect to the number of banks, one can say that the application of this criterion is justified by all the formal criteria: the sample of 49-bank collection; the study is carried out on the same set of items with the introduction of the benefits and the same items after the introduction of the benefits. Accordingly, it is possible to determine a positive impact of the tax exemption on charitable expenses of the studied banks.

This criterion will allow one to establish the statistically significant $(\mathrm{p}<0,01)$ differences at the level of charitable expenditure "before introduction of the benefits", that is, the existing volume, which a bank could spend without relying on economic incentives, and "after introduction of the benefits", i.e. volume of charity expenses derived within the model.

It should be noted that the amount of banks' charitable expenses, considering the minimum limit of $1 \%$, is statistically different from the existing expenses. Thus, this measure could really increase the volume of charitable expenses, supposing that the companies having these benefits would have used the privilege to increase their spending on this line. The average volume of charitable expenditure, obtained by the analysis of the test sample in the models with different limits, is shown in Fig. 4. The figure shows that the existing average volume of charitable expenditure is 173.6 million rubles. Setting the maximum limit of charitable expenditure for tax purposes of $1 \%$, the average costs could increase to 189 million rubles and gradually would grow to 197.4 million rubles at $10 \%$ limit.

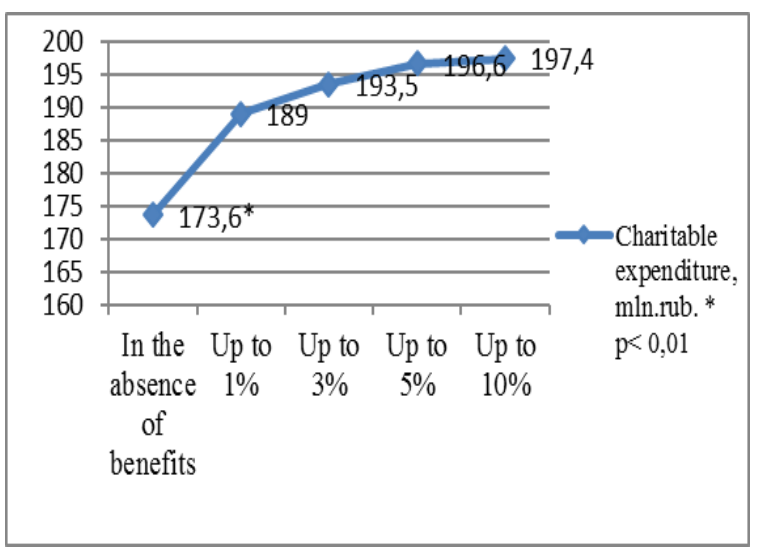

Fig. 4. Dynamics of the average volume of charitable expenses of the banking sector after the introduction of tax incentives

Figure 4 shows that the average volume of charitable expenditure varies depending on the set limit, as each limit forms different potential to increase the charitable expenses depending on the existing volume of each bank's expenses. One of the most important tasks is to determine the optimal, most efficient limit of charitable expenses for tax purposes. Earlier, it was already established that the limit of $1 \%$ can be considered the least effective. Accordingly, to establish the effectiveness of one of the remaining options, let's determine whether the difference in the limits of $3 \%$ to $5 \%$ to $10 \%$ is statistically significant. The authors used the Friedman test with the application of the Newman-Keyls test to compare the limits pairwise.

After the establishment of statistically significant differences between the various options, we used the modification of Newman-Keyls to compare the options altogether. To check the reliability of the model this criterion was applied to the study sample. Each modeled volume of 
charitable expenditure received on the same set of banks for each of the three limit options was compared to another one.

Table 3 shows the dimensions obtained for the NewmanKeyls criterion for different limits of charitable expenses. Based on these values, one can conclude that there is a statistically significant difference between the limits of $3 \%$ and $10 \%$ in terms of charitable expenditure within the model, and in terms of lost tax revenues due to the impact of the preferential taxation mechanism. Establishing the limit of $10 \%$ would lead to an increase in charitable expenses for organizations that spend more than the limit of $5 \%$ to charity. At the same time, this will increase the losses of tax revenues, due to increased tax benefits for companies that spend more than the limit of $10 \%$ anyway. Accordingly, the limit of $10 \%$ is not considered the most effective.

TABLE III. THE INDICATORS OF NEWMAN-KEYLS CRITERIA FOR THE STUDY SAMPLE OF BANKS FOR THE YEARS 2011-2014

\begin{tabular}{|c|c|c|c|c|}
\hline Comparison & $\begin{array}{c}\text { Indicators of } \\
\text { the Newman- } \\
\text { Keyls } \\
\text { criterion to } \\
\text { charitable } \\
\text { expenditure } \\
\text { increasing }\end{array}$ & $\mathrm{P}<0.05$ & $\begin{array}{c}\text { Indicators } \\
\text { of the } \\
\text { Newman- } \\
\text { Keyls } \\
\text { criterion to } \\
\text { the tax } \\
\text { revenue } \\
\text { foregone } \\
\text { increasing }\end{array}$ & P $<0,05$ \\
\hline $\begin{array}{c}\text { Up to } 10 \% \text { and } \\
\text { up to 3\% }\end{array}$ & 3.47256 & Yes & 3.980933 & Yes \\
\hline $\begin{array}{c}\text { Up to } 10 \% \text { and } \\
\text { up to 5\% }\end{array}$ & 0.834058 & No & 2.919202 & Yes \\
\hline $\begin{array}{c}\text { Up to 5\% and up } \\
\text { to 3\% }\end{array}$ & 3.440488 & Yes & 2.710687 & No \\
\hline
\end{tabular}

\section{CONCLUSION}

As the literature review has shown, over the recent decades the importance of the alternative (in comparison with the direct subsidies) sources of finance for non-profit organizations as providers of public goods and services has been growing. One such source that has several advantages over direct financing is preferential tax treatment for charitable activities.

In conclusion, with regard to the analysis of the quality indicators that show support for charity, the study demonstrates that, most banks publish information about their charity activities on their official websites. Nearly a half had a sustainable charitable strategy; they work with the same partners, provide aid to the same recipients, and have the same priorities in charity for a long time. At the same time, using the advantage of corporate philanthropy in special forms is fairly rare in banking. The study has also found that, for every limit, of charitable expenditure for tax purpose, most banks have a potential for maximum growth of donations (from $49.5 \%$ to $74 \%$ depending on the set limit). These results suggest that the introduction of preferential tax treatment for charitable activities could boost the flow of financial resources for socially important areas.

The study showed no difference between losses in tax revenue of $3 \%$ and $5 \%$ limit, taking into account the costs of charity. Thus, the limit of $5 \%$ was not significantly different from $10 \%$ in terms of hypothetical charitable expenditure, but at the same time, does not differ from the level of $3 \%$ in terms of tax benefits.

Accordingly, one can conclude that an optimal limit of charitable expenses for tax purposes is 5\% of the taxable profit. It is the most efficient in terms of charitable expenses growth at minimum losses. This means that the limit is high enough, but it does not exceed the volume of existing charitable spending that most companies spend without economic stimulation. At the same time, this limit is low enough not to increase the budget losses due to uncollected tax revenues. One should highlight that the volume of banks' charitable expenses even setting the minimum limit of $1 \%$, is statistically significantly different from existing expenditures. Thus, this measure can really reduce the cost of charitable expenses, if the companies having the benefit will use the privilege to increase their spending on charity.

\section{Acknowledgment}

This work was funded by the RFFR grant № №17-2201002/17 "Elaboration the Tax Experiments in the System of Tax Avoidance Counteraction for the Economic Security Provision in the Russian Federation and Belarus" (State registration number in FGASI CITaS: $A A A A-A 17-1170404)$.

\section{References}

[1] J. Andreoni, J. Miller, "Giving according to GARP: An experimental test of the consistency of preferences for altruism", Econometrica, vol. 70, №. 2, pp. 737-753, 2002.

[2] K. S. Barrett, A. M. McGuirk, R. Steinberg, "Further evidence on the dynamic impact of taxes on charitable giving", National Tax Journal, vol. 50(2), pp. 321-334, 1997.

[3] R. Bennett, "Corporate philanthropy in France, Germany and the UK: International comparisons of commercial orientation towards company giving in European nations" International Marketing Review, vol. 15, №. 6, pp. 458-475, 1998.

[4] L. Burianová, J. Paulík, "Corporate Social Responsibility in Commercial Banking - A Case Study from the Czech Republic", Journal of Competitiveness, vol. 6, pp. 50-70, 2014.

[5] C. T. Clotfelter et al, "The economics of giving" in J. W. Barry and B. V. Manno (eds.), Giving better, giving smarter: Working Papers of the National Commission on Philanthropy and Civic Renewal, Washington, DC: National Commission on Philanthropy and Civic Renewal, pp. 3155. 1997.

[6] C. T. Clotfelter, C. E. Steuerle, "Charitable Contributions", In How Taxes Affect Economic Behavior, edited by Henry J. Aaron and Joseph A. Pechman. Washington, D.C.: Brookings Institution, p.456, 1981.

[7] M. Cornett, "Corporate Social Responsibility and its Impact on Financial Performance: Investigation of the U.S. Commercial Banks", Presentation at the Bentley University Council's Research Colloquium on the topic of "Responsible Innovation: Environmental Sustainability, Financial Accountability, and Information and Communication Technology (ICT) Ethics, Bentley University, 2013.

[8] D. G. Duff, 'Tax Treatment of Charitable Contributions in Canada: Theory, Practice, and Reform", Osgoode Hall Law Journal, vol. 42, pp.1-72. 2004. 
[9] G. Fack, C. Landais, "Are tax incentives for charitable giving efficient? Evidence from France", American Economic Journal: Economic Policy, vol. 2, pp. 117-141, 2010.

[10] D. Feenberg, "Are tax price models really identified: The case of charitable giving", National Tax Journal, vol.40 (4), pp. 629-633, 1987.

[11] J.A. Johnson, The Determinants of Charitable Giving with Special Emphasis on the Income Deduction under the Income Tax - A Survey of the Empirical Literature, Canada: Tax Poly, p.258, 1981.

[12] A. Kireenko, S. Golovan, "Feasibility of the charitable tax deduction introduction in the Russian Federation", Journal of Tax Reform, Vol. 2. №2, pp. 111-125, 2016.

[13] M. Pinskaya, "Approaches to understanding the tax equity", Journal of Tax Reform, Vol. 1, №1, pp. 90-99, 2015.

[14] W. C. Randolph, "Dynamic income, progressive taxes, and the timing of charitable contributions", Journal of Political Economy, vol.103(4) pp.709-738. 1995.

[15] K. Scharf, B. Cherniavsky, R. Hogg, Tax incentives for charities in Canada, Ottawa Canadian Policy Research Networks, p.51. 1997.

[16] R. Steinberg, "Taxes and giving: new findings", International Journal of Voluntary and Nonprofit Organizations, vol. 34, pp. 61-79, 1990. 